\title{
Restricted rotation of the amino group and ring inversion in substituted thienopyridines. A dynamic NMR and quantum mechanical study
}

\author{
Matthias Heydenreich, Andreas Koch, Jochen Woller, and Erich Kleinpeter* \\ Universität Potsdam, Institut für Organische Chemie und Strukturanalytik, Am Neuen Palais 10, \\ D-14415 Potsdam \\ E-mail: heydenr@chem.uni-potsdam.de
}

\begin{abstract}
Dedicated to Prof. Kalevi Pihlaja on the occasion of his $60^{\text {th }}$ birthday (received 14 Dec 00; accepted 01 Jan 99; published on the web 18 Apr 02)
\end{abstract}

\begin{abstract}
A series of six- and eight-membered ring-fused aminothiophenes 1-8 was investigated in terms of the height of the rotational barrier of the amino group by dynamic ${ }^{1} \mathrm{H}$ NMR spectroscopy and quantum chemical methods. The restricted rotation around the $\mathrm{N}-\mathrm{C}\left(\mathrm{sp}^{2}\right)$ bond depends only on steric influences of the fused ring. The compounds with the eight-membered fused ring show a decreased barrier to rotation. This is caused by the increased steric energy of their ground states and similar energies of all calculated transition states. In these cases, the steric hindrance leads to a wider deviation of the amino group from planarity. Thus, the $\pi$-conjugation to the thiophene ring is more disturbed and the energy difference between ground and transition state is lowered.

An additional dynamic process of the eight-membered rings was observed and could be classified as ring inversion which is sterically hindered by the neighboured protons of the amino group.
\end{abstract}

Keywords: Amino group, restricted rotation, ring inversion, thienopyridines, dynamic NMR, quantum mechanical study

\section{Introduction}

Thieno[2,3-b]pyridines are known to be biologically active compounds. They show bactericide activities against Staphylococcus aureus and Pseudomonas aeruginosa ${ }^{1}$, fungicide activities against Venturia inaequalis ${ }^{2}$ and act as neuroleptica and tranquilizer ${ }^{3}$. To understand biological mechanisms of these bioactive compounds it is necessary to investigate not only their minimum energy conformations, but also their intramolecular flexibilities. One of the most important interactions between ligands and receptors are hydrogen bridges. Therefore, not only the 
orientation of hydrogen donors and acceptors of the ligand molecules in their ground states but also the flexibility of these molecules are essential for their biological activity. For that major reason, some amino derivatives of a series of fused thieno[2,3-b]pyridines ${ }^{4}$ 1-8 (Scheme) were synthesized and studied by dynamic NMR spectroscopy and quantum chemical calculations with respect to their geometry and intramolecular flexibility.

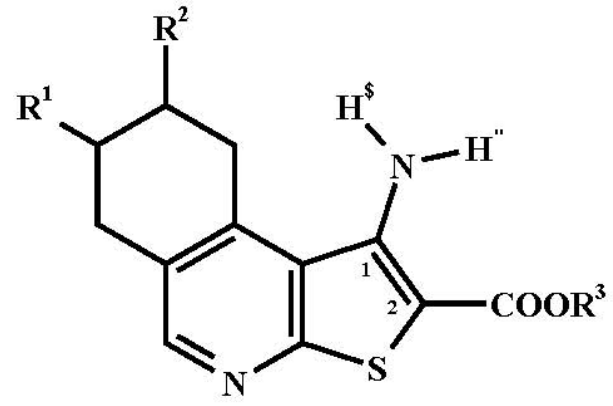

$1-6$

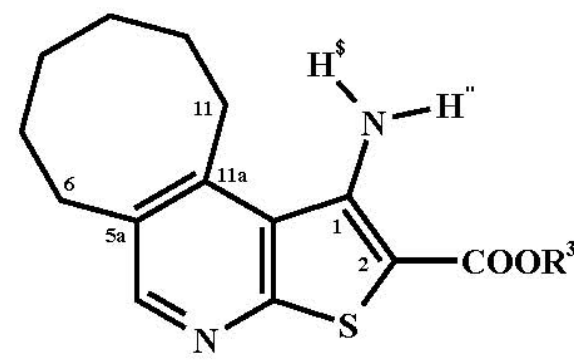

$7, \mathbf{8}$

\begin{tabular}{lllllllll}
\hline Compound & 1 & 2 & 3 & 4 & 5 & 6 & 7 & 8 \\
\hline
\end{tabular}

$\begin{array}{lllllll}\mathrm{R}^{1} & \mathrm{H} & \mathrm{H} & \mathrm{Me} & \mathrm{Me} & \mathrm{H} & \mathrm{H}\end{array}$

$\begin{array}{lllllll}\mathrm{R}^{2} & \mathrm{H} & \mathrm{H} & \mathrm{H} & \mathrm{H} & \mathrm{Me} & \mathrm{Me}\end{array}$

$\begin{array}{lllllllll}\mathrm{R}^{3} & \mathrm{Me} & \mathrm{Et} & \mathrm{Me} & \mathrm{Et} & \mathrm{Me} & \mathrm{Et} & \mathrm{Me} & \mathrm{Et}\end{array}$

\section{Scheme 1}

The low-temperature ${ }^{1} \mathrm{H}$ NMR spectra of 1-8 show decoalescence of the amino protons in agreement with the frozen rotation about the $\mathrm{C}\left(\mathrm{sp}^{2}\right)-\mathrm{NH}_{2}$ bond. This dynamic process will be studied along this work in dependence on electronic and steric substituent effects and the influence of intramolecular hydrogen bonds. The free energies of activation $\left(\Delta \mathrm{G}^{\#}\right)$ were estimated experimentally by variable-temperature ${ }^{1} \mathrm{H}$ NMR spectroscopy and compared with results from quantum chemical calculations. In $\mathbf{7}$ and $\mathbf{8}$ a second dynamic process was identified. By analyzing the NOESY spectra of these compounds and the observed energy barrier this process was assigned to the ring inversion of the eight-membered ring moiety.

\section{Results and Discussion}

The barrier height of the restricted rotation of the amino group bound to (hetero)aromatic systems proved dependent on several influences, e.g. on bulky ortho substituents or on intra- or intermolecular hydrogen bonds to at least one of the amino hydrogens as discussed previously. ${ }^{5}$ Recently, the restricted rotation of the amino group in 5-amino-2-acyl-1,2,4-thiadiazolin-3-ones 
was studied and the barrier to rotation found to be ca. $61 \mathrm{~kJ} / \mathrm{mol}$. This value is relatively high taking into account the absence of an intramolecular hydrogen bond and of bulky ortho substituents. Only the formation of a partial C,N double bond, like in amides, can explain this high value. ${ }^{6}$

The influence of an intramolecular hydrogen bond between one amino proton and an adjacent thioaldehyde substituent in thiophene derivatives was investigated and found to be in the range of $10-12 \mathrm{~kJ} / \mathrm{mol}^{7}$

The barriers to rotation of the amino group in 1-8 (Scheme) are given in Table 1. The influence of the ester group (Me or Et ester) is only minor and within the range of the experimental error of measurement. A significant difference in the free energy of the restricted rotation $\left(\Delta \mathrm{G}^{\#}\right)$ was found only between six-membered $(\mathbf{1}-\mathbf{6})$ and eight-membered $(\mathbf{7}$ and $\mathbf{8})$ ring systems. Compounds 7 and 8 show a lower barrier (ca. $2-3 \mathrm{~kJ} / \mathrm{mol}$ ) than the other compounds with a six-membered fused ring. Further methyl substitution at the six-membered fused ring in positions 7 or 8 (compounds $3-6$ ) is also only of negligible influence on the barrier height. In order to better understand the lower barriers to rotation of the compounds with the eightmembered fused ring, quantum chemical calculations were carried out. Both ground and transition states were investigated. Similarities and differences will be discussed in the following (cf. Tab. 2).

Table 1. Experimental and calculated data of the compounds $\mathbf{1}-\mathbf{8}$ : free energies of activation $\left(\Delta \mathrm{G}^{\#}\right)$ of the restricted rotation of the amino group, their coalescence temperatures, calculated steric energies of the ground states, energy differences between ground and transition states and free energy differences between ground and transition state 1

\begin{tabular}{ccccccc}
\hline Compound & $\begin{array}{c}\Delta \mathrm{G}^{\#} \\
(\mathrm{~kJ} / \mathrm{mol})\end{array}$ & $\begin{array}{c}\mathrm{T}_{\mathrm{c}} \\
(\mathrm{K})\end{array}$ & $\begin{array}{c}\text { Steric } \\
\text { energy } \\
{[\mathrm{kJ} / \mathrm{mol}]}\end{array}$ & $\begin{array}{c}\text { Energy } \\
\text { difference } \\
\text { GS-TS1 } \\
{[\mathrm{kJ} / \mathrm{mol}]}\end{array}$ & $\begin{array}{c}\text { Energy } \\
\text { difference } \\
\text { GS-TS2 } \\
{[\mathrm{kJ} / \mathrm{mol}]}\end{array}$ & $\begin{array}{c}\text { Free energy } \\
\text { difference }\left(\Delta \mathrm{G}^{\#}\right) \\
\text { GS-TS1 } \\
{[\mathrm{kJ} / \mathrm{mol}]}\end{array}$ \\
\hline 1 & 37.8 & 208 & 10.22 & 29.29 & 62.15 & 25.72 \\
2 & 37.2 & 205 & 10.22 & 29.10 & 62.29 & 25.51 \\
3 & 37.7 & 207 & 9.96 & 29.22 & 61.93 & 25.70 \\
4 & 37.2 & 205 & 9.96 & 29.02 & 62.06 & 25.53 \\
5 & 37.5 & 206 & 11.09 & 29.47 & 62.29 & 25.73 \\
6 & 38.2 & 210 & 11.05 & 29.27 & 62.45 & 25.54 \\
7 & 35.1 & 194 & 14.16 & 26.67 & 61.06 & 23.21 \\
8 & 34.8 & 193 & 14.15 & 25.75 & 60.84 & 22.48 \\
\hline
\end{tabular}

${ }^{a}$ Steric energy means the strength of pairwise interactions between localized orbitals: between the $\sigma$ orbitals of the $\mathrm{N}-\mathrm{H}^{\beta}$ bond and the nearest $\mathrm{C}-\mathrm{H}$ bond of the fused ring. 
Table 2. Geometry of both ground state (GS) and transition state (TS) calculated at the HF/6$31 \mathrm{G}^{* *}$ level

\begin{tabular}{|c|c|c|c|c|c|c|}
\hline Compound & $\begin{array}{c}\text { Distance } \\
\mathrm{H}^{\beta}- \\
\mathrm{H}(\mathrm{ring}) \\
{[\AA]}\end{array}$ & $\begin{array}{c}\text { Distance } \\
\mathrm{H}^{\alpha}-\mathrm{O} \\
{[\AA]}\end{array}$ & $\begin{array}{c}\text { Sum of angles } \\
\text { (amino group) } \\
\left.{ }^{\circ}\right]\end{array}$ & $\begin{array}{c}\text { Torsional } \\
\text { angle } \\
\mathrm{C} 2-\mathrm{C} 1-\mathrm{N}-\mathrm{H}^{\alpha} \\
\left.{ }^{\circ}\right]\end{array}$ & $\begin{array}{c}\text { Torsional } \\
\text { angle } \\
\text { C2-C1-N-H } \\
\left.{ }^{\circ}{ }^{\circ}\right]\end{array}$ & $\begin{array}{c}\text { Torsional } \\
\text { angle } \\
\text { C1-C2-C }=\mathrm{O} \\
\left.{ }^{\circ}\right]\end{array}$ \\
\hline $1(\mathrm{GS})$ & 2.175 & 2.051 & 344.86 & 8.7 & 145.3 & 0.6 \\
\hline $1(\mathrm{TS})$ & 2.898 & 2.580 & 323.74 & 56.0 & -58.3 & -0.2 \\
\hline $2(\mathrm{GS})$ & 2.177 & 2.050 & 344.63 & 8.7 & 145.0 & 0.6 \\
\hline $2(\mathrm{TS})$ & 2.898 & 2.580 & 323.64 & 55.9 & -58.3 & -0.2 \\
\hline $3(\mathrm{GS})$ & 2.179 & 2.501 & 345.12 & 8.9 & 145.8 & 0.5 \\
\hline $3(\mathrm{TS})$ & 2.921 & 2.583 & 323.74 & 56.2 & -58.1 & -0.2 \\
\hline $4(\mathrm{GS})$ & 2.181 & 2.050 & 344.96 & 8.9 & 145.6 & 0.5 \\
\hline 4 (TS) & 2.922 & 2.581 & 323.65 & 56.2 & -58.0 & -0.2 \\
\hline $5(\mathrm{GS})$ & 2.149 & 2.050 & 344.65 & 8.6 & 145.0 & 0.6 \\
\hline $5(\mathrm{TS})$ & 2.873 & 2.574 & 323.71 & 55.8 & -58.5 & -0.2 \\
\hline $6(\mathrm{GS})$ & 2.152 & 2.048 & 344.41 & 8.6 & 144.6 & 0.6 \\
\hline $6(\mathrm{TS})$ & 2.874 & 2.573 & 323.63 & 55.8 & -58.4 & -0.2 \\
\hline 7 (GS) & 2.056 & 2.044 & 342.42 & 7.3 & 140.8 & 0.9 \\
\hline 7 (TS) & 2.820 & 2.580 & 323.69 & 57.7 & -56.6 & -0.1 \\
\hline $8(\mathrm{GS})$ & 2.059 & 2.043 & 342.23 & 7.3 & 140.6 & 0.9 \\
\hline $8(\mathrm{TS})$ & 2.820 & 2.574 & 323.57 & 57.7 & -56.5 & -0.2 \\
\hline
\end{tabular}

All calculated compounds show a slightly pyramidal arrangement of the amino group in their ground states and a stronger one in their transition states (sum of bond angles $<360^{\circ}$ ). In $\mathbf{7}$ and $\mathbf{8}$, the pyramidal character of their ground states is more distinct, caused by their stronger steric hindrance ( $c f$. Tab.1). First, the larger and therefore bulkier ring leads to a shortening of the distance between one of the $\mathrm{NH}_{2}$ hydrogens $\left(\mathrm{H}^{\beta}\right)$ and the adjacent $\mathrm{CH}_{2}$ group in the fused ring (position 9 in $\mathbf{1}$ - 6, position 11 in $\mathbf{7}$ and 8) by ca. $0.12 \AA$. The distance of the second $\mathrm{NH}_{2}$ hydrogen $\left(\mathrm{H}^{\alpha}\right)$ to the carbonyl oxygen remains unaffected to be with a value of 2.04 and $2.05 \AA$ in the range of a strong intramolecular hydrogen bond. This intramolecular hydrogen bond is positioned in all compounds approximately in the thiophene ring plane: the torsional angle between $\mathrm{C} 2$ and $\mathrm{H}^{\alpha}$ was found of $c a$. 7 to 9 degrees, the torsional angle between $\mathrm{C} 1$ and the carbonyl oxygen of the ester group is only slightly out of plane $\left(0.1^{\circ}\right.$ to $\left.0.9^{\circ}\right)$.

Second, the value of the torsional angle between the thiophene ring plane and the $\mathrm{NH}_{2}$ moiety $\left(\mathrm{C} 2-\mathrm{C} 1-\mathrm{N}-\mathrm{H}^{\beta}\right)$ was calculated to be smaller in 7 and $\mathbf{8}\left(\mathrm{ca} .141^{\circ}\right)$ than in $\mathbf{1}-\mathbf{6}\left(\mathrm{ca} .145^{\circ}\right)$. Thus, in all compounds investigated the amino group proved not only to be pyramidal but also to be non-planar with the thiophene ring moiety: the amino nitrogen atom was calculated to be slightly out of this plane (ca. $3^{\circ}$ ) (cf. Fig. 1). Such an ,out of plane“ structure of the amino group was already determined by an X-ray structural analysis of the bulky 2-methyl-5-nitroaniline ${ }^{8}$ and 
is also known from a series of urea derivatives. ${ }^{9}$

The transition states of all calculated compounds are very similar. They are characterized (i) by a higher pyramidal character of the amino group regarding to their ground states (sum of angles of the amino group is lowered by $c a .20^{\circ}$ ), (ii) by the breaking of the intramolecular hydrogen bond, and (iii) by similar torsional angles of the two hydrogens $\mathrm{H}^{\alpha}$ and $\mathrm{H}^{\beta}$ to the thiophene ring plane (cf. Figure. 1).
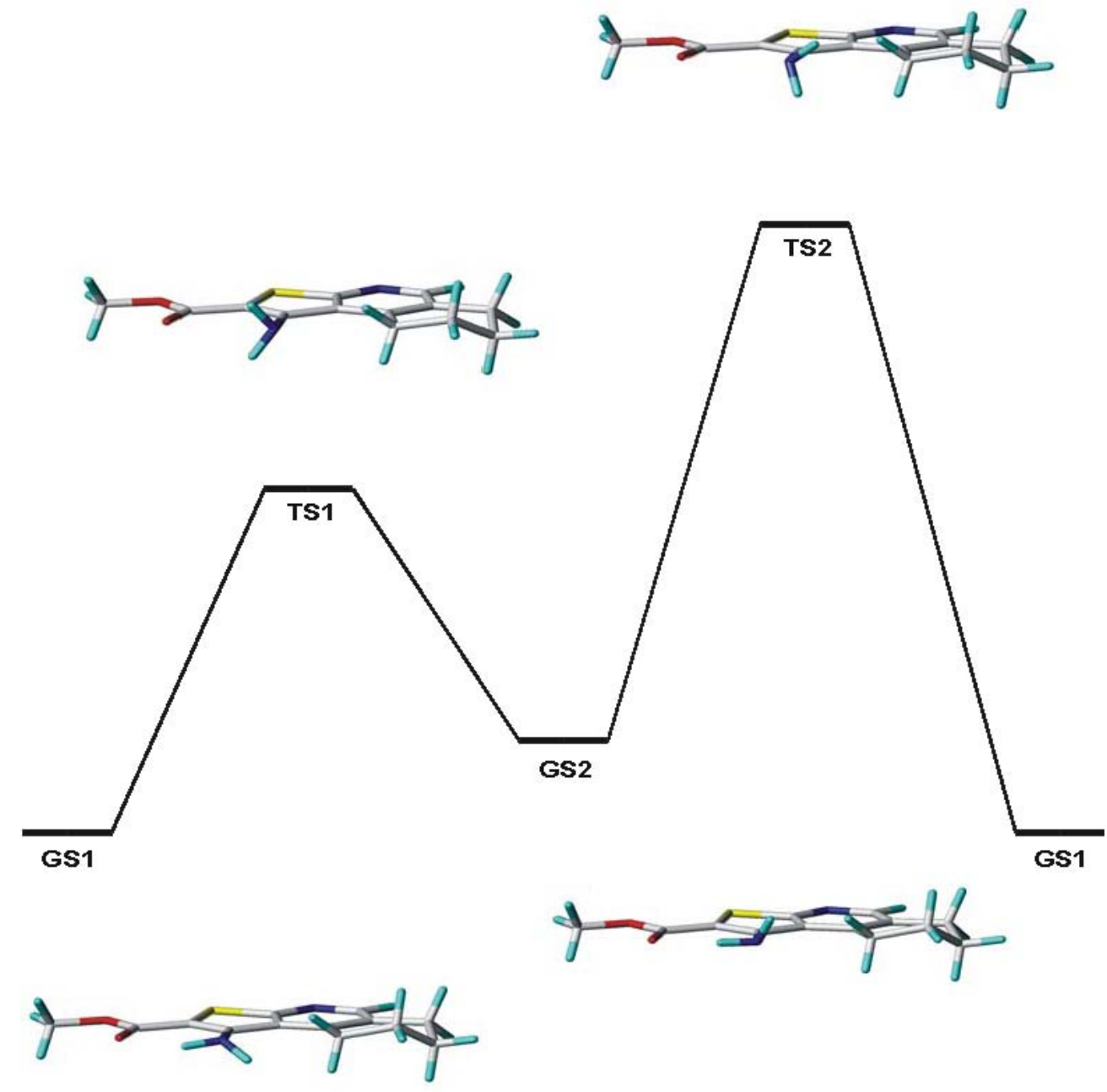

Figure 1. Calculated stationary points of the amino group rotation of compound $\mathbf{1}$. The molecule is given in its two transition states (top) and its two ground states (bottom).

Comparing both the ground and transition states, the difference in the barriers to rotation between the compounds with the six- and the eight-membered fused rings can be explained by the steric influence of the different ring sizes on the ground states only. The quantum chemical calculations of the steric interaction of $\mathrm{H}^{\beta}$ and the nearest $\mathrm{CH}_{2}$ hydrogen of the ring system, using the NBO 4.0 program ${ }^{10}$, show a ca. $4 \mathrm{~kJ} / \mathrm{mol}$ higher interaction energy in the eight-membered 
fused rings. This interaction causes the larger non-planarity of the $\mathrm{NH}_{2}$ group and hereby the weaker $\pi$-conjugation along the whole $\mathrm{H}$ bond chelate to the thiophene moiety. The free energy of the ground states of the eight-membered ring systems 7 and $\mathbf{8}$ is increased by ca. $2.6 \mathrm{~kJ} / \mathrm{mol}$ due to this steric effect. This is in good agreement with the experimental difference to the barriers to rotation of the six-membered ring analogues $(2-3 \mathrm{~kJ} / \mathrm{mol})$.

The differences between calculated and experimentally determined barriers to rotation can be explained by the fact that calculations were carried out for both ground and transition states in vacuum. Thus, solvent influences were not taken into account.

In compounds $\mathbf{7}$ and $\mathbf{8}$ a second dynamic process including the eight-membered ring was observed. The aliphatic ring $\mathrm{CH}_{2}$ protons, spatially near to the amino group, are splitting at low temperatures. Room temperature NOESY spectra of $\mathbf{7}$ and $\mathbf{8}$ unequivocally assign protons by cross peaks between the $\mathrm{NH}_{2}$-protons and $11-\mathrm{CH}_{2}$ and the pyridine ring proton and $6-\mathrm{CH}_{2}$. Additionally, a cross peak between $6-\mathrm{CH}_{2}$ and $11-\mathrm{CH}_{2}$ indicates a slightly twisted boat-chair conformation of the attached eight-membered ring. The dynamic process leads to an exchange of the pseudo-axial and pseudo-equatorial hydrogens at $11-\mathrm{CH}_{2}$, corroborating the ring inversion. The pseudorotation as the dynamic process was ruled out because in this case a change of pseudo-axial and pseudo-equatorial positions could not be observed.

The obtained free energies of activation $\left(\Delta \mathrm{G}^{\#}\right)$ of the barrier to ring inversion in 7 (44.3 $\mathrm{kJ} / \mathrm{mol}, 221 \mathrm{~K})$ and $8(43.8 \mathrm{~kJ} / \mathrm{mol}, 220 \mathrm{~K})$ are slightly higher than given in the literature for cyclooctene- $\mathrm{d}_{13}(34.3 \mathrm{~kJ} / \mathrm{mol})^{11}$ and cyclooctene derivatives $(31.8-34.3 \mathrm{~kJ} / \mathrm{mol}){ }^{12}$ The theoretical calculations of this process in compound 7 at the HF/6-31G** level gave an energy of $53.6 \mathrm{~kJ} / \mathrm{mol}$ for the barrier to ring inversion, the calculated free energy of activation $\left(\Delta \mathrm{G}^{\#}\right)$ was found to be $50.2 \mathrm{~kJ} / \mathrm{mol}$. The differences between calculated and observed values may be due to the used quantum chemical approximations as mentioned above. One of the ground states and the transition state are shown in Figure. 2. The calculations showed that the steric hindrance between the protons of the amino group and the $11-\mathrm{CH}_{2}$ protons especially in the transition state influences the height of the barrier of this dynamic process. This may be the reason for the observed higher barrier of ring inversion in comparison to the literature data.
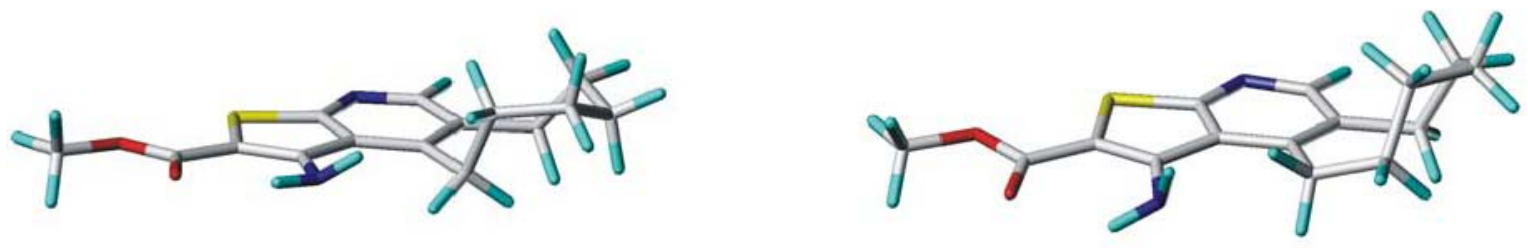

Figure 2. Ground (left) and transition state (right) of the ring inversion of 7 . The process leads to an exchange of the pseudo-axial and pseudo-equatorial protons in position 11 .

The process was also observed by molecular dynamic simulation at a temperature of $500 \mathrm{~K}$ 
and a time scale of 300 ps. In Figure. 3 the time-dependent torsional angle between H11 - C11 - C11a - C5a is presented. It can be clearly seen that the equatorial position $\left(\mathrm{H} 11_{\mathrm{eq}}\right)$ with a starting torsional angle of $c a .150^{\circ}$ changes into the axial position with a torsional angle of $c a$. $40^{\circ}$ after $c a .80 \mathrm{ps}$ and later (at $c a .120 \mathrm{ps)}$ it changes back to the former position in complete agreement with the ring inversion process.

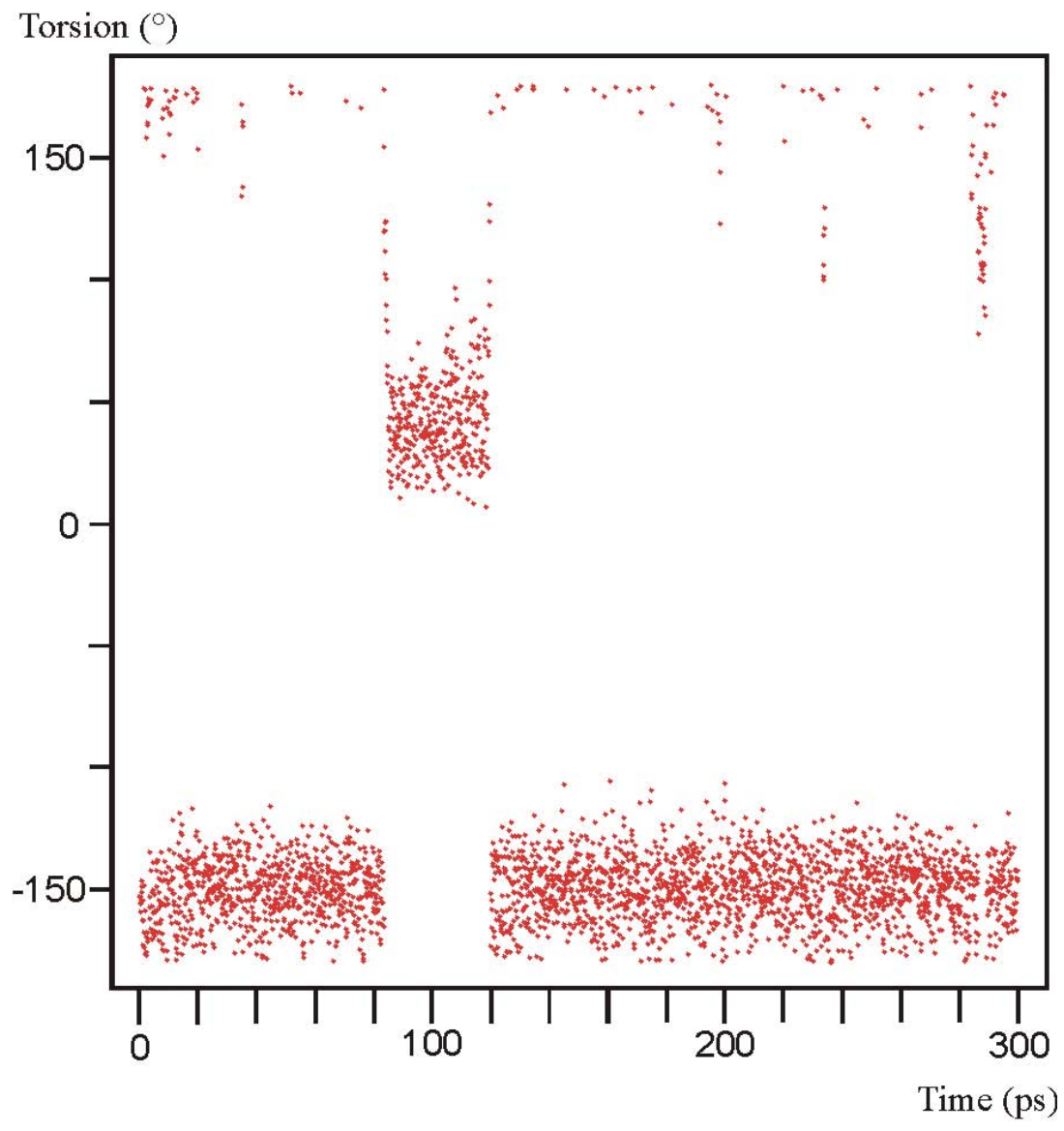

Figure 3. Torsional angle (one proton $\mathrm{H} 11-\mathrm{C} 11-\mathrm{C} 11 \mathrm{a}-\mathrm{C} 5 \mathrm{a}$ ) at different times during the dynamic simulation of compound 7.

\section{Experimental Section}

\section{NMR-Spectroscopy}

All NMR spectra were recorded using an ARX 300 (Bruker) with a temperature control unit VT 1000. The samples were measured as ca. $0.1 \mathrm{~m}$ solutions in $\mathrm{CD}_{2} \mathrm{Cl}_{2}$. All solutions were prepared as follows: after cooling below the melting point of the system the sample tube was evacuated and then warmed up to room temperature. This cycle was repeated five times and than the tubes were sealed. 


\section{Quantum chemical calculations}

The $a b$ initio calculations were carried out with the GAUSSIAN $98^{13}$ program at the HF/6-31G** level of theory. ${ }^{14}$ The calculations contain a complete optimization of the conformations without any constraints. In order to predict the energy of the systems at room temperature, thermal energy corrections were added to the total energy, which includes the effects of molecular translation, rotation and vibration at the temperature of $298.15 \mathrm{~K}$ and normal pressure.

The transition states of the rotation of the amino groups in 1-8 and the dynamics of the eightmemberd ring in 7 were determined using the QST3 ${ }^{15}$ algorithm. The stationary points were characterized by analytical calculation of the second derivatives of the energies.

The steric interactions were calculated using the NBO - natural steric analysis. ${ }^{16}$ Natural steric analysis expresses the energy associated with exchange repulsion as the corresponding energy difference due to orbital orthogonalization. The strength of pairwise interactions between localized orbitals falls off rapidly with the distance, so the steric effects due to interaction of the interested number of orbitals in close proximity can be shown by a list of pairwise terms. These steric interactions can be a measure of atom atom interactions in a molecule.

The NBO calculations were done with the program NBO $4.0^{10}$ implemented in GAUSSIAN98. Molecular dynamics simulations (TRIPOS force field) ${ }^{17}$ were carried out at 500 $\mathrm{K}$ under isobar conditions for $300 \mathrm{ps}$ with time steps of $1 \mathrm{fs}$. Snap shots were made every $100 \mathrm{fs}$.

\section{Synthesis}

The syntheses of the compounds $\mathbf{1}-\mathbf{8}$ and their NMR spectra are described in Ref. ${ }^{4}$

\section{Conclusions}

The barrier height of the restricted rotation of the amino group in the title compounds $\mathbf{1}-\mathbf{8}$ depends on the size of the fused alicyclic ring, but not on the size of the ester group in 2-position. Quantum chemical calculations show that steric interactions between the fused ring and the amino group are accountable for the differences in the measured free energy $\left(\Delta \mathrm{G}^{\#}\right)$ to rotation about the $\mathrm{N}-\mathrm{C}\left(\mathrm{sp}^{2}\right)$ bond. The reason for this difference could be calculated to be the increased steric energy of the ground state of the compounds with the eight-membered fused rings, whereas the transition states of all compounds investigated were found to be very similar.

The ring inversion in compounds $\mathbf{7}$ and $\mathbf{8}$ is also hindered by the steric influence of the amino protons. In the compounds 1-6 the six-membered ring did not show any dynamic effects during the variable-temperature NMR measurements.

Both NMR methods and theoretical calculations were found to complement themselves and were able to correctly and completely describe the dynamic behavior of the compounds studied. 


\section{Acknowledgements}

The support of the Deutsche Forschungsgemeinschaft (DFG-Gz. INK 16B/1) is gratefully acknowledged.

\section{References}

1. (a) Tanaka, K.; Sutani, M.; Komatsu, M.; Tsuchida, K.; Saito, A.; Hayashi, K.; Kanna,H.; Goto, A.; Minami, S.; Watanabe, Y. JP 06041149, 1992; Chem. Abstr. 1994, 121, 108364; (b) Tanaka, K.; Sutani, M.; Komatsu, M.; Tsuchida, K.; Saito, A.; Hayashi, K.; Kanna, H.; Goto, A.; Minami, S.; Watanabe, Y. JP 05331175, 1992; Chem. Abstr. 1994, 121, 108362; (c) Tanaka, K.; Sutani, M.; Komatsu, M.; Tsuchida, K.; Saito, A.; Hayashi, K.; Kanna, H.; Yonezawa, K.; Minami, S.; Watanabe, Y. JP 05202065, 1991; Chem. Abstr. 1994, 120, 134144.

2. Mellor, M.; Riordan, P. D. GB 9313664, 1992; Chem. Abstr. 1994, 120, 106972.

3. Hrib, N. J.; Jurcak, J. G. US 5272148, 1992; Chem. Abstr. 1994, 120, 245156.

4. Woller, J.; Spindler, K.; Sarodnick G.; Kempter, G. Pharmazie 1996, 51, 937.

5. Heydenreich, M.; Koch, A.; Kleinpeter E.; Zimmermann, T. Fresenius J. Anal. Chem. 1997, 357, 517 and cited literature herein.

6. Ra, D. Y.; Cho, N. S.; Moon J. H.; Kang, S. K. J. Heterocyclic Chem. 1998, 35, 1435.

7. Lunazzi, L.; Mazzanti, A.; Spagnolo P.; Degl'Innocenti, A. J. Org. Chem. 1997, 62, 2263.

8. Ellena, J.; Punte G.; Rivero, B. E. J. Chem. Crystallogr. 1996, 26, 319.

9. (a) Mido, Y. J. Mol. Struct. 1981, 72, 3. (b) Mido Y.; Furusawa, C. J. Mol. Struct. 1982, 82, 23. (c) Galabov, B.; Kalcheva V.; Hadjieva, B. J. Mol. Struct. 1989, 213, 317. (d) Hadjieva, B.; Kalcheva V.; Galabov, B. J. Mol. Struct. 1990, 238, 439. (e) Lumbroso, H.; Liégeois, C.; Devillanova F. A.; Verani, G. J. Mol. Struct. 1981, 77, 239. (f) Godfrey, P. D.; Brown R. D.; Hunter, A. N. J. Mol. Struct. 1997, 413, 405. (g) Kim, W.; Lee, H.-J.; Choi J.-H.; Yoon, C.-J. J. Chem. Soc., Faraday Trans. 1998, 94, 2663. (h) Witanowski, M.; Sicinska, W.; Biedrzycka Z.; Webb, G. A. J. Mol. Struct. 1999, 476, 133.

10. NBO 4.0. Glendening, E. D.; Badenhoop, J. K.; Reed, A. E.; Carpenter J. E.; Weinhold, F. Theoretical Chemistry Institute, University of Wisconsin, Madison: WI, 1996.

11. Oki, M. In Applications of Dynamic NMR Spectroscopy to Organic Chemistry; VCH Publishers Inc.: Deerfield Beach, 1985, p 316.

12. Anderson, J. E.; Casarini, D.; Lunazzi, L. J. Chem. Soc. Perkin Trans.2 1991, 1425.

13. Gaussian 98, Revision A.5; Frisch, M. J.; Trucks, G. W.; Schlegel, H. B.; Scuseria, G. E.; Robb, M. A.; Cheeseman, J. R.; Zakrzewski, V. G.; Montgomery, Jr., J. A.; Stratmann, R. E.; Burant, J. C.; Dapprich, S.; Millam, J. M.; Daniels, A. D.; Kudin, K. N.; Strain, M. C.; Farkas, O.; Tomasi, J.; Barone, V.; Cossi, M.; Cammi, R.; Mennucci, B.; Pomelli, C.; Adamo, C.; Clifford, S.; Ochterski, J.; Petersson, G. A.; Ayala, P. Y.; Cui, Q.; Morokuma, 
K.; Malick, D. K.; Rabuck, A. D.; Raghavachari, K.; Foresman, J. B.; Cioslowski, J.; Ortiz, J. V.; Stefanov, B. B.; Liu, G.; Liashenko, A.; Piskorz, P.; Komaromi, I.; Gomperts, R.; Martin, R. L.; Fox, D. J.; Keith, T.; Al-Laham, M. A.; Peng, C. Y.; Nanayakkara, A.; Gonzalez, C.; Challacombe, M.; Gill, P. M. W.; Johnson, B.; Chen, W.; Wong, M. W.; Andres, J. L.; Gonzalez, C.; Head-Gordon, M.; Replogle, E. S.; Pople, J. A.: Gaussian Inc., Pittsburgh PA, 1998.

14. Hehre, W. J.; Radom, L.; v. R. Schleyer, P.; Pople, J. A. Ab Initio Molecular Orbital Theory, Wiley: New York, 1986.

15. (a) Peng, C.; Ayala, P.Y.; Schlegel, H. B.; Frisch, M. J. J. Comp. Chem. 1996, 17, 49. (b) Peng, C.; Schlegel, H. B. Israel J. Chem. 1993, 33, 449.

16. Badenhoop, J. K.; Weinhold, F. 'Natural Bond Orbital Analysis of Steric Interactions A, University Wisconsin Theoretical Chemistry Institute Technical Report WIS-TCI-833, 1995. 17. SYBYL 6.6; TRIPOS Inc., 1699 S. Hanley Road, St. Louis, MO, 1999. 